Article

\title{
Capillary Uptake Monitoring in Lime-Hemp-Perlite Composite Using the Time Domain Reflectometry Sensing Technique for Moisture Detection in Building Composites
}

\author{
Przemysław Brzyski ${ }^{1, *(1)}$ and Zbigniew Suchorab 2 (1) \\ 1 Faculty of Civil Engineering and Architecture, Lublin University of Technology, Nadbystrzycka Str. 40, \\ 20-618 Lublin, Poland \\ 2 Faculty of Environmental Engineering, Lublin University of Technology, Nadbystrzycka Str. 40B, \\ 20-618 Lublin, Poland; z.suchorab@pollub.pl \\ * Correspondence: p.brzyski@pollub.pl; Tel.: +48-5384448
}

Received: 18 March 2020; Accepted: 31 March 2020; Published: 3 April 2020

\begin{abstract}
The use of waste plants in the production of building materials is consistent with the principles of sustainable development. One of the ideas involves using hemp shives as an aggregate for the production of a composite used as a filling of the timber frame construction of the walls. The most important disadvantage of using the building materials based on organic components is their susceptibility to the water influence. The wall material is exposed to rising groundwater. The research part of the paper presented the preparation method and the investigation of the hemp-perlite-lime composites. Flexural and compressive strength, apparent density, total porosity, thermal conductivity, and mass absorptivity were examined. The main research part pertained to the analysis of capillary uptake occurrence in the composites, being the important phenomenon present in the external walls. The study on this phenomenon was carried out using the technique of indirect moisture evaluation-Time Domain Reflectometry (TDR). The indirect readouts were additionally verified with the traditional evaluation using the gravimetric method based on the PN-EN 1925 standard. The study proved that the tested composites were characterized by low apparent density, thermal conductivity, strength parameters, high total porosity, and mass absorptivity. The partial replacement of hemp shives by expanded perlite had a beneficial effect on the tested properties of composites.
\end{abstract}

Keywords: hemp-lime composites; capillary uptake; time domain reflectometry; material moisture; thermal conductivity

\section{Introduction}

Within recent years, numerous scientific reports on the utilization of vegetal materials in the building sector have been published. It is a consequence of the growing interest of potential investors in natural building. Such kind of houses, besides their ecological aspects (that are not influencing regular lives), is also beneficial for the residents due to the healthy microclimate. The high porosity of vegetal materials also influences the appropriate thermal insulation parameters [1]. The hygroscopic character creates the ability to adjust the moisture levels in the indoor rooms. The walls that are made of straw or hemp composites are properly combined with clay, which is usually applied for wall plastering. Clay is also a favorable material for people with allergic diseases because it has the ability to absorb various types of dust. Additionally, the above-mentioned natural materials are characterized by high diffusivity permeability, which protects the walls from the vapor condensation inside the envelope or on internal surfaces, which would lead to mold development. Scientific research is currently being 
conducted on the different natural materials that could be utilized as building materials. The examples include cut sunflower stalk mixed with gypsum binder [2] as insulation board, sisal fibers [3] as scattered reinforcement, flax [4] as an element of chipboards, hemp fibers and shives [5] in mortars, flax or hemp fibers as thermal insulation [6], but also ligneous parts of stalks cut into shives of hemp used as aggregate for the composites based on lime binder $[7,8]$.

The most important disadvantage related to the usage of building materials based on organic components is their susceptibility to the water influence [9]. Natural protection over extensive moisture in the boundaries that are built of natural, vegetal materials usually constitutes the thick layers of clay or lime plaster. In dry ambient air, these materials can absorb the water from the wall structure and transport it to the air [10].

In the case of the building materials applied for walls construction, an important feature is the ability of capillary uptake of groundwater. The capillary forces depend on the quantity, dimension, and orientation of the open pores in the material [11]. The visible consequence of the capillary uptake phenomenon is the moisture present at the bottom levels of the walls, reaching various heights depending on the material parameters [12]. Besides the visual aspects of capillary uptake, the decrease of thermal parameters of material [13] and finally rotting of the wooden elements of the wall should be mentioned as well. In order to prevent this phenomenon in the newly built boundaries, horizontal waterproofing layers should be applied between the foundation and the wall.

The article presented the results of the research on the capillary uptake ability of water by the composites comprising the wastes from local hemp. The moisture performance of the three types of composites that differ in the ratio of binder to filler and have different amounts of two kinds of fillers (hemp shives and expanded perlite) was presented. The capillary uptake process was examined with two methods: gravimetric (based on the PN-EN 1925 standard [14]) and the reflectometric technique of indirect moisture detection-Time Domain Reflectometry (TDR). Additionally, for wider material recognition, the basic properties of the composites, such as the flexural and compressive strength, apparent density, total porosity, thermal conductivity, and mass absorptivity, were examined as well.

Time Domain Reflectometry (TDR) is a technique applied to determine the apparent permittivity of porous materials with the measurement of the electromagnetic pulse propagation time along the rods of the measuring probes. The essentials of the technique are described in detail in the following articles $[15,16]$. Apparent permittivity is a measured parameter, describing the behavior of the molecules under the alternate electromagnetic field and the dissipation of the energy after the field is released. This measure can be determined using the TDR equipment, and its value depends on the moisture of the material. According to the physical and empirical models available in the literature [15,17-23], its value depends on the shares of particular phases forming the material. Water has the most dominant influence on the TDR readouts due to its polar particle character and the fact that its apparent permittivity value amounts to about 80 [-]. It is significantly greater than the apparent permittivity of the solid 3-10 [-] and air 1 [-] phase [24-27]; the difference contributes to the potential of the TDR as a measuring technique for moisture estimation of many porous media.

The TDR technique has been intentionally applied in the field of soil science to evaluate the moisture content of the soils. However, several approaches to utilize its potential for evaluating the moisture of construction materials have been noted in the scientific literature. Most of the investigations on building materials are conducted using the traditional, invasive probes used for soils [28-32]. Several attempts have been also made to evaluate the moisture of building materials by the co-authors of this article $[33,34]$

\section{Materials and Methods}

\subsection{Description of Materials}

The research was conducted on the composite based on a modified lime (L) binder and aggregate substitute involving hemp $(\mathrm{H})$ shives and expanded perlite $(\mathrm{P})$ (Three recipes that differed in the 
proportion of the applied compounds were investigated. The first recipe (HL1) contained only hemp shives as an aggregate substitute, the other two compositions (HLP1 and HLP2) besides shives also contained expanded perlite. The same binder was used in all recipes. It was a mixture of hydrated lime CL-90s (Lhoist, Tarnów, Poland) (70\% of binder dry mass) with metakaolin (Astra Polska, Gdańsk, Poland) and Portland cement CEM I 42.5R (Cemex, Chełm, Poland)—both 15\% of binder dry mass. This mixture created a binder, which was called artificial hydraulic lime. Hydrated lime was an air binder with low strength parameters. However, it was characterized by high vapor permeability and resistance to biological corrosion due to high $\mathrm{pH}$ value. Metakaolin was a highly reactive pozzolanic material, which was formed in the kaoline clay calcination process under controlled temperature conditions of around $600-850{ }^{\circ} \mathrm{C}$. Its main ingredient was hydrated aluminum silicate $\mathrm{Al}_{2} \mathrm{Si}_{2} \mathrm{O}_{5}(\mathrm{OH})_{4}$. This additive has been used in other studies of the hemp-lime composite [35].

The formulas of the tested composites are presented in Table 1 (amounts by weight per $1 \mathrm{~m}^{3}$ ) and in Table 2 (proportions by weight).

Table 1. Mixture amounts (by weight).

\begin{tabular}{ccccc}
\hline Material & Binder & Hemp Shives & Expanded Perlite & Water \\
\hline symbol/unit & $\left(\mathrm{kg} / \mathrm{m}^{3}\right)$ & $\left(\mathrm{kg} / \mathrm{m}^{3}\right)$ & $\left(\mathrm{kg} / \mathrm{m}^{3}\right)$ & $\left(\mathrm{kg} / \mathrm{m}^{3}\right)$ \\
\hline HL1 & 284.44 & 142.22 & - & 412.44 \\
HLP1 & 334.44 & 101.33 & 65.87 & 484.88 \\
HLP2 & 250.80 & 101.33 & 65.87 & 413.82 \\
\hline
\end{tabular}

Table 2. Mixture proportions (by weight).

\begin{tabular}{ccccc}
\hline Material/Symbol & Binder & Hemp Shives & Expanded Perlite & Binder: Water Ratio \\
\hline HL1 & 2 & 1 & - & 1.45 \\
HLP1 & 2 & 0.6 & 0.4 & 1.45 \\
HLP2 & 1.5 & 0.6 & 0.4 & 1.65 \\
\hline
\end{tabular}

The hemp shives applied in all four recipes were Polish type of the industrial hemp named Białobrzeskie (the Institute of Natural Fibers and Medicinal Plants, Poznań, Poland). It was adapted to the local, Polish soil-climatic conditions. The hemp filler was characterized with high total porosity, about $90 \%$, which has also been confirmed by literature (90.1 $\pm 0.5 \%$ [36]), and low apparent density, about $130 \mathrm{~kg} / \mathrm{m}^{3}$, as in other studies (about $125 \pm 9 \mathrm{~kg} / \mathrm{m}^{3}$ [36]). The applied mixture of hemp shives was characterized by a large diversity in length, width, and thickness of fractions. The weight shares of particular fractions are presented in Figure 1. A mixture of shives also contained small amounts of hemp fibers and dust.

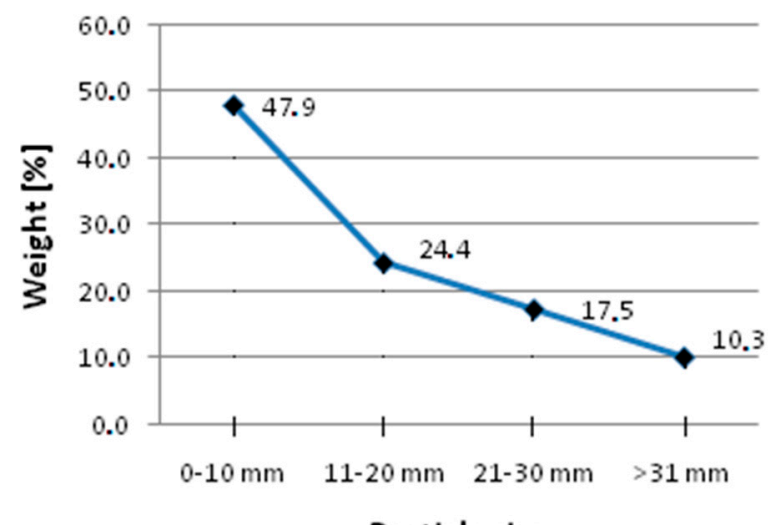

Particle size

Figure 1. Grading curve of the hemp shives used in the study. 
EP180 (Perlit Polska, Puńców, Poland), second class perlite with granulation of 0-4 mm, was applied for the HLP1 and HLP2 composites. The perlite content in relation to the binder content was from $20 \%$ to $30 \%$. The compression strength of the perlite was $0.14-0.40 \mathrm{MPa}$, bulk density $80-100 \mathrm{~kg} / \mathrm{m}^{3}$, and heat conductivity coefficient $0.042 \mathrm{~W} /(\mathrm{m} \cdot \mathrm{K})$ [37]. The perlite additives were applied in order to achieve a compacted structure by filling the air gaps between the randomly arranged hemp shives. Additionally, it was expected that perlite additives should decrease the intensity of the capillary uptake phenomenon and minimize the threat of mold and fungus development. The fillers used in the tests are shown in the figure below (Figure 2).

a)

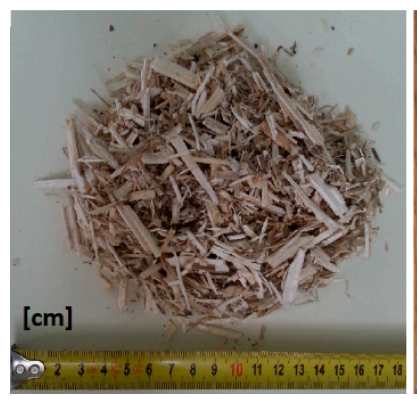

b)

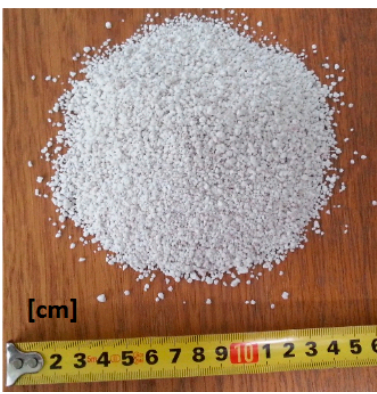

Figure 2. Fillers in composites: (a) hemp shives, (b) expanded perlite.

Water was also applied as a mixture compound with the precisely established amounts for the hemp-lime composites. Only the minimal possible amount of water necessary for binding was used because the excessive water would lead to an increase in drying time. Under the extreme circumstances, it might cause the disintegration of mixture compounds and thus storage of the binder in the bottom parts of wall boarding or escape of the binder through the leaks in the boards.

\subsection{Sample Production Process}

The sample preparation process involved the binder mixing with water and gradual supplementation of the liquid binder to the initially mixed fillers, maintaining the constant mixing. The mixing procedure lasted until the hemp shives and the perlite were covered with a binder, and the mixture obtained a homogenous consistency. A similar procedure of mixing could be found in the following papers [38,39]. On the other hand, Cerezo and Nguyen, in their research, firstly soaked the hemp shives and then supplemented them to the mixed binder materials [40,41]. Next, the samples were formed. Due to the presence and the shape of the lightweight filler, mixture compaction under gravity was not possible. The samples were thickened by hand beating with a wooden peg with a diameter of $30 \mathrm{~mm}$.

\subsection{Determination of Composite Parameters}

\subsubsection{Apparent Density and Porosity}

In order to parameterize the material, its basic physical features were determined. Apparent density, specific density, and open and total porosity of the composites were measured. The measurements were conducted according to the PN-EN 12390-7 standard [42]. Total porosity was estimated as a ratio of the total volume of open and closed pores per sample volume.

\subsubsection{Flexural and Compressive Strength}

The strength tests were conducted using an MTS 810 apparatus (MTS System Corporation, Eden Prairie, MN, USA) with the range of load between 0-100 kN. The flexural strength was estimated using samples with a dimension of $100 \times 100 \times 500 \mathrm{~mm}$. The compressive strength was determined on samples with the following dimensions $150 \times 150 \times 150 \mathrm{~mm}$. Displacement of the compressing head 
was set to $1 \mathrm{~mm} / \mathrm{min}$ (flexural strength test) and $3 \mathrm{~mm} / \mathrm{min}$ (compressive strength test). The average of three attempts was assumed as the measurement readout.

\subsubsection{Thermal Conductivity}

The thermal conductivity determination was conducted using the samples with the dimensions of $300 \times 300 \times 50 \mathrm{~mm}$ after 28 days of maturing. The measurement was conducted using the FOX314 plate apparatus (TA Instruments, New Castle, DE, USA). Before the experiment, the samples were dried to constant mass. In order to achieve the average temperature of $12.5^{\circ} \mathrm{C}$, the heating plate temperature was set to $25^{\circ} \mathrm{C}$ and the cooling plate to $0{ }^{\circ} \mathrm{C}$. The result of the research was an average of the heat conductivity coefficient of the composite achieved in three attempts for each recipe.

\subsubsection{Mass Absorptivity}

The absorptivity is the ability to absorb water at atmospheric pressure. The mass absorptivity tests were conducted according to the PN-EN 13755:2008 [43] standard on three $100 \times 100 \times 100 \mathrm{~mm}$ specimens for each recipe. The samples were completely submerged in water. Its result was the ratio between the mass of the absorbed water and the mass of the dry sample.

\subsubsection{Capillary Uptake (Standard Method)}

This experimental test was conducted in accordance with the PN-EN 1925 standard [14]. Three samples of each recipe, with the dimensions of $150 \times 150 \times 150 \mathrm{~mm}$, were placed in contact with water at a depth of approximately $10 \mathrm{~mm}$ and maintained at a constant level by using a tank water system. In the determined intervals of time, the increase in the mass of samples was noticed. In this way, the amount of water absorbed was determined. An increase of the mass of the samples was measured in the following intervals of time: $1 \mathrm{~h}, 3 \mathrm{~h}, 6 \mathrm{~h}, 12 \mathrm{~h}, 24 \mathrm{~h}, 3 \mathrm{~d}, 4 \mathrm{~d}, 6 \mathrm{~d}, 10 \mathrm{~d}$.

\subsubsection{Capillary Uptake (TDR Method)}

The capillary uptake experiment was conducted using Time Domain Reflectometry (TDR) method by applying the following equipment:

- Set of TDR field probes for moisture determination (FP/mts, EasyTest, Lublin, Poland),

- TDR multimeter with multiplexer (LOM, EasyTest, Lublin, Poland),

- PC for multimeter control and data processing,

- Software to control TDR multimeter and post-process the obtained data,

- Dryer (Memmert VO-500),

- Water container,

- Samples of the examined composite with the dimensions of $150 \times 150 \times 150 \mathrm{~mm}$.

The measurement was conducted on 3 samples for each recipe (nine samples were tested). Three TDR probes were inserted in vertical line into each sample according to the figures below (Figures 3 and 4) at the following heights 25, 75, and $125 \mathrm{~mm}$ above the water level.

The samples were placed in a water container with a constant water table. The bottom surface of each sample was placed $10 \mathrm{~mm}$ below the water level. In order to prevent the water absorbed by samples from surface evaporation, the samples were covered with anti-diffusive foil. The TDR probes were inserted horizontally according to the compaction direction, which was simulating a building barrier made of composite placed monolithically in the wall formworks. The duration of the experiment was set to 44 days. The time step was set for $15 \mathrm{~min}$. The experiment was conducted under laboratory conditions at a temperature of $22 \pm 2{ }^{\circ} \mathrm{C}$ and relative humidity of $60 \pm 5 \%$. 


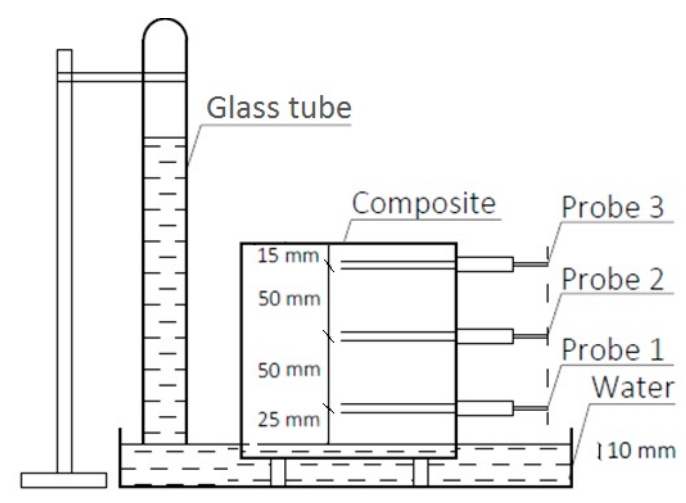

Figure 3. Schematic view of the measuring setup.

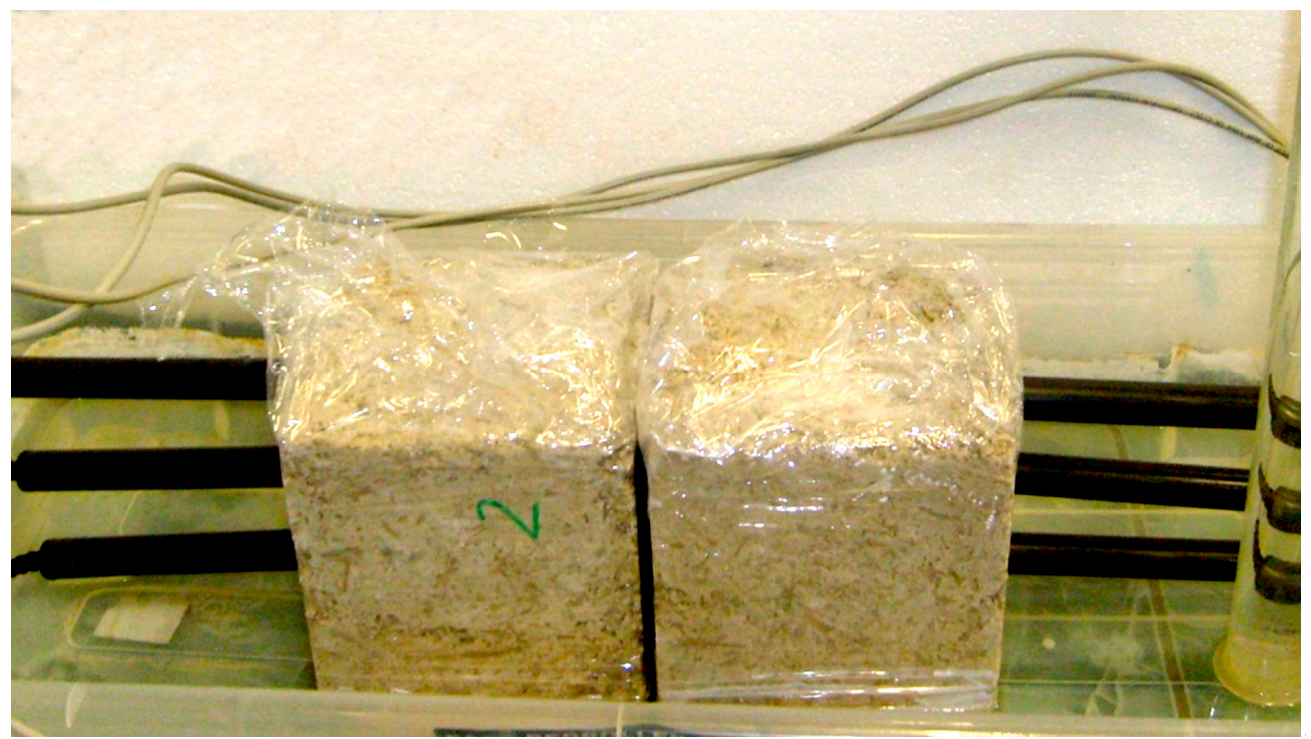

Figure 4. Photography of two samples examined with the experiment with installed Time Domain Reflectometry (TDR) FP/mts probes.

During the experiment, the values of the apparent permittivity were read by means of the TDR equipment. They were later recalculated into the volumetric water content using semi-empirical Malicki's calibration model [23]:

$$
\theta=\frac{\left(\varepsilon^{0,5}-0.819-0.168 \rho-0.159 \rho^{2}\right)}{7.17+1.18 \rho}
$$

where $\theta$-volumetric water content $\left(\mathrm{cm}^{3} / \mathrm{cm}^{3}\right) ; \rho$-bulk density of the composite $\left(\mathrm{g} / \mathrm{cm}^{3}\right) ; \varepsilon$ —apparent permittivity value measured using TDR (-).

According to the literature sources, the applied calibration model is efficient in the moisture evaluation of the materials with the various features of the solid phase [27], and the measurement uncertainty is about $0.02 \mathrm{~cm}^{3} / \mathrm{cm}^{3}$ (2 vol \%) [44-46].

\section{Results and Discussion}

Table 3 presents the results of individual tests (averaged values) pertaining to the basic mechanical and physical properties of the composites used in the experiment. The analysis of the results is presented in the following subsections. 
Table 3. Mechanical and physical properties of composites (average value \pm SD).

\begin{tabular}{ccccccccc}
\hline \multirow{2}{*}{$\begin{array}{c}\text { Recipe } \\
\text { Symbol }\end{array}$} & $\begin{array}{c}\text { Flexural } \\
\text { Strength }\end{array}$ & $\begin{array}{c}\text { Compressive Apparent } \\
\text { Strength }\end{array}$ & $\begin{array}{c}\text { Total } \\
\text { Density }\end{array}$ & $\begin{array}{c}\text { Open } \\
\text { Porosity } \\
\text { Porosity }\end{array}$ & $\begin{array}{c}\text { Mass } \\
\text { Absorptivity Absorptivity }\end{array}$ & $\begin{array}{c}\text { Volume } \\
\text { Conductivity } \\
\text { Coefficient }\end{array}$ \\
\cline { 2 - 9 } & $\mathbf{( M P a )}$ & $\mathbf{( M P a )}$ & $\mathbf{( k g / \mathbf { m } ^ { 3 } )}$ & $\mathbf{( \% )}$ & $\mathbf{( \% )}$ & $\mathbf{( \% )}$ & $\mathbf{( \% )}$ & $\mathbf{( W / ( m \cdot K ) )}$ \\
\hline HL1 & 0.18 & 0.66 & 497.9 & 74.4 & 57.8 & 112.6 & 56.1 & 0.108 \\
& \pm 0.018 & \pm 0.019 & \pm 5.25 & \pm 0.451 & \pm 0.251 & \pm 4.52 & \pm 2.35 & \pm 0.004 \\
\hline HLP1 & 0.23 & 0.78 & 503.1 & 75.6 & 49.9 & 90.1 & 45.3 & 0.111 \\
& \pm 0.026 & \pm 0.025 & \pm 6.35 & \pm 0.491 & \pm 0.203 & \pm 3.93 & \pm 2.02 & \pm 0.005 \\
\hline HLP2 & 0.16 & 0.55 & 417.5 & 79.3 & 54.3 & 127.8 & 53.4 & 0.087 \\
& \pm 0.013 & \pm 0.014 & \pm 5.80 & \pm 0.547 & \pm 0.242 & \pm 5.48 & \pm 2.37 & \pm 0.002 \\
\hline
\end{tabular}

\subsection{Apparent Density and Porosity}

The apparent density of the examined composites was between 417.5 and $503.1 \mathrm{~kg} / \mathrm{m}^{3}$ (Table 3). According to the conducted experiment and literature review, it mainly depends on the method of compaction $[47,48]$ and the proportion between the binder and the aggregate. Together with the increase of the binder share in the mixture, the density of composite arose, which could be also confirmed by the following literature reports [48,49].

There is also a strict dependence between volumetric density and apparent porosity, which comes directly from its definition. The high porosity of hemp shives, amounting to about $60 \%$, and their position during compaction influenced high total porosity of a composite- $74.4-79.3 \%$ as well as open porosity between $49.9 \%$ and $57.8 \%$ (Table 3). According to Rahim's research [50], the porosity of hemp composites is comparable-the composite with a volumetric density of $478 \mathrm{~kg} / \mathrm{m}^{3}$ indicates total porosity to be equal to $76.4 \%$ and open porosity $49.9 \%$. The total porosity of hemp shives with a volumetric density of $125 \mathrm{~kg} / \mathrm{m}^{3}$ equals to $90.1 \%$ with the shives fraction of about $5 \times 5 \times 15 \mathrm{~mm}$. In a hardened composite, it is possible to distinguish pores, being the consequence of the uneven position of shives in the material and those present between hydrates in the binder matrix [47], but also the pores present in the shives structure.

According to [1], for the composites applied as a roof thermal insulation with the apparent density of $258 \mathrm{~kg} / \mathrm{m}^{3}$, it is possible to obtain porosity of $84.9 \%$, and by the increase of density to $457 \mathrm{~kg} / \mathrm{m}^{3}$, required to use composites for prefabrication, porosity decreases to $72 \%$. In another research, Collet [1] presented that the composite fabricated for walls rising using spraying revealed the total porosity of $79 \%$ and open porosity below $70 \%$ with the densities of $430-460 \mathrm{~kg} / \mathrm{m}^{3}$. The research presented in [51] has investigated the composites with densities of $256-460 \mathrm{~kg} / \mathrm{m}^{3}$ and porosities of $80-72 \%$, respectively.

\subsection{Flexural and Compressive Strength}

The average value of the flexural strength of composites reached from 0.16 to $0.23 \mathrm{MPa}$ and compressive strength between 0.55 to $0.78 \mathrm{MPa}$ (Table 3). A hemp-lime composite can be applied to fill the timber frame construction. It is a self-supporting material, which means that it supports its own weight and also stiffens the timber construction [52]. The increase of strength is directly combined with the decrease of other important physical parameters, such as density rise, thermal resistance decrease [49]. According to the conducted research, as well as the literature reports, the parameter of the composite, which influences strength to the greatest extent, is the binder share in relation to the aggregate $[48,49]$. The highest compressive strength was reached by the composites with a weight ratio between binder and aggregate 2:1. Those were HLP1 $\left(0.78 \mathrm{MPa}, 503.1 \mathrm{~kg} / \mathrm{m}^{3}\right)$ and HL1 $(0.66 \mathrm{MPa}$, $\left.497.9 \mathrm{~kg} / \mathrm{m}^{3}\right)$.

\subsection{Thermal Conductivity}

The thermal conductivity coefficient of the examined composites comprised of values between $0.087 \mathrm{~W} /(\mathrm{m} \cdot \mathrm{K})$ and $0.111 \mathrm{~W} /(\mathrm{m} \cdot \mathrm{K})$. The value of this parameter depended mainly on the ratio between 
the binder and the filler, which was 2:1 and 1.5:1. The highest value of the $\lambda$ coefficient was measured for the HLP1 composite with the highest apparent density equal to $503.1 \mathrm{~kg} / \mathrm{m}^{3}$. On the other hand, for the HLP2 composite with the highest porosity equal to $79.3 \%$, the heat conductivity was the lowest. What is important that the partial replacement of the hemp shives with expanded perlite, which was used in the HLP1 and HLP2 composites, did not unequivocally influence the value of heat conductivity of the composites. The elevated binder content influences the increase of the apparent density of composite and, thus, the increase of heat conductivity [1]. The amount of hemp aggregate in the compound of composite influences the value of its heat conductivity coefficient; however, it must be noticed that it is not a linear dependence [48]. According to the cited reports, it has been revealed that despite the higher porosity, higher thermal conductivity has been observed in the handmade composites in the wall formworks than in those applied by spraying. It could be also connected with higher heat conductivity of particular compounds-a greater amount of hemp fibers, which are less porous than shives. The work published by [48] presents the value of heat conductivity coefficient for the composite with an apparent density of $377 \mathrm{~kg} / \mathrm{m}^{3}$ to be equal to $0.089 \mathrm{~W} /(\mathrm{m} \cdot \mathrm{K})$, and for another composite with an apparent density of $603 \mathrm{~kg} / \mathrm{m}^{3}$, it is equal to $0.141 \mathrm{~W} /(\mathrm{m} \cdot \mathrm{K}$ ). The chart (Figure 5) presents a comparison of the exemplary relations between the lambda coefficient and the apparent density of the hemp-lime composites.

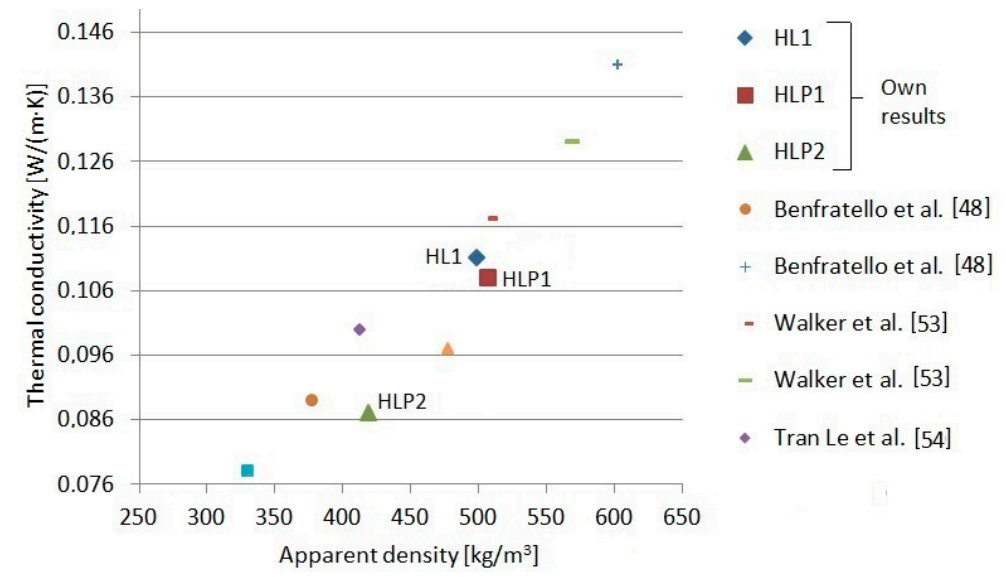

Figure 5. Relationship between the lambda coefficient and the apparent density of the hemp-lime composites $[48,53,54]$.

\subsection{Mass Absorptivity}

The graph (Figure 6) presents the results of the tested composites.

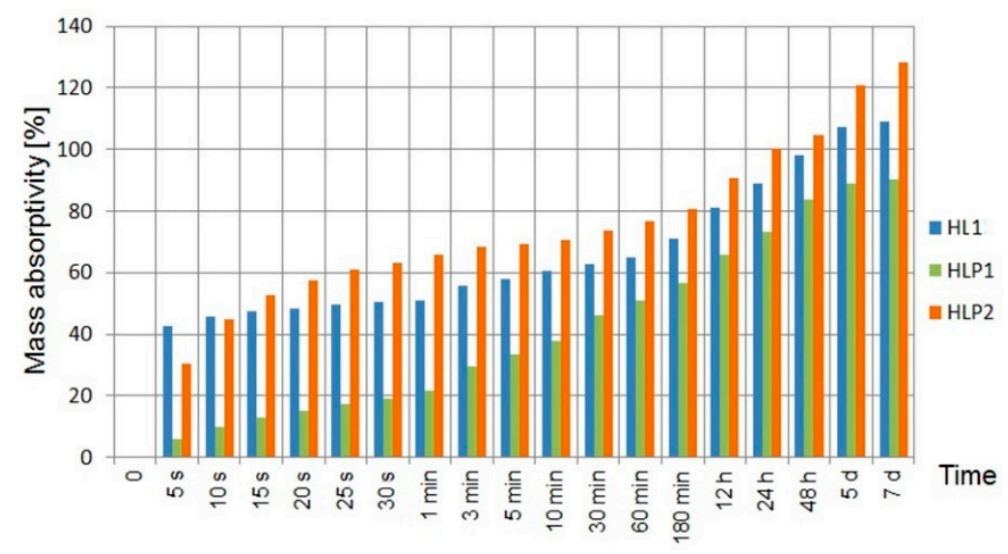

Figure 6. Mass absorptivity of composites. 
The hemp shives themselves are able to absorb water in the amount of twice their own weight in the first $5 \mathrm{~s}$ after immersion in water [55]. The largest difference was recorded after the first $5 \mathrm{~s}$ since the samples were immersed in water when HL1 reached the absorbability of about 7.3 times higher compared to HLP1 and about 1.4 times higher compared to HLP2. The addition of expanded perlite as a part of the filler proved to be effective. Despite the small difference in the porosity of the samples with and without perlite, the perlite-containing samples obtained a more compact and homogeneous structure, which caused the limitation of water absorption in the first seconds of the study. Similar observations have been described in the literature [56]. Comparing HL1 and HLP1 composites, which contained the same weight ratio of filler to filler equal to 2:1, the perlite-containing composite (HLP1) was characterized by about $20.5 \%$ lesser water absorption than the sample containing only the hemp shives as a filler (HL1). The ratio of binder to the filler also had a significant effect on the absorptivity of the composites. The composite with the ratio of binder to the filler 1.5:1 (HLP2) showed greater water absorption than the composite with a ratio of 2:1 (HLP1) by $425 \%$ after $5 \mathrm{~s}$ and by $42 \%$ after 7 days of immersion in water.

The presented test method was designed to simulate extreme conditions-a situation in which part of the wall was flooded for a period of 7 days. Long-term exposure of the hemp-lime composite to water might result in the development of fungi and molds; however, after 7 days of testing, no signs of biological corrosion or other forms of material damage were observed. The research results showed that the greatest increase in the water absorption occurred within the $5 \mathrm{~s}$ from the moment of immersion of the samples in water. In practice, this could happen under temporary rainfall.

Water absorptivity strictly depends on the density of the material, which, in turn, is related to the proportion of binder to the shives, as well as their fractions. Stevulova showed [57] that it was possible to limit the absorption of water to about $25 \%$; however, this result was achieved by examining a composite with a bulk density of $1070 \mathrm{~kg} / \mathrm{m}^{3}$, a fraction of 4-8 mm shives, and a volume composition of shives: binder: water-40:29:31\%. Sassoni, in turn, in the studies [58] applied a composite density range from 300 to $1300 \mathrm{~kg} / \mathrm{m}^{3}$. After $24 \mathrm{~h}$ of wetting, the samples with a density of $300 \mathrm{~kg} / \mathrm{m}^{3}$ showed absorbability of $118.4 \%$, while the composite with the highest density, i.e., $1300 \mathrm{~kg} / \mathrm{m}^{3}$, showed significantly lower absorbability of $10.1 \%$.

\subsection{Capillary Uptake Test Results by the TDR Equipment}

Apparent permittivity determined with the TDR equipment was recalculated into volumetric water content using the Equation (1), taking into consideration the bulk density of the tested composites. The graphs below (Figures 7-9) show the volumetric water contents at different levels of the sample at the time intervals obtained from the TDR test on the three tested composites.

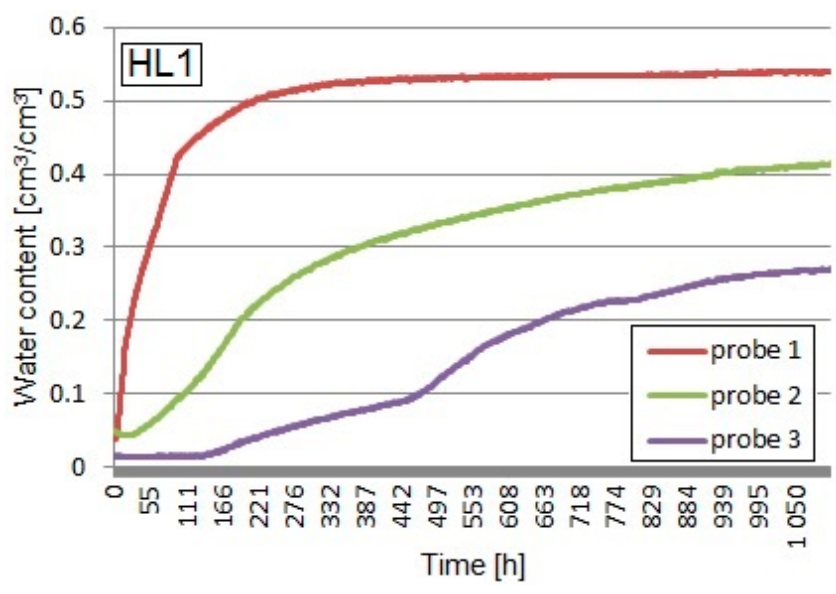

Figure 7. Capillary uptake of the HL1 composite. 


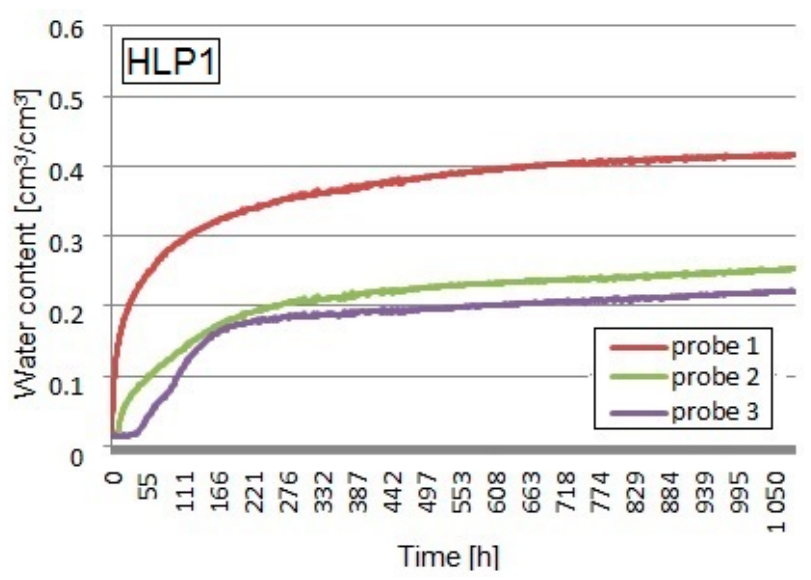

Figure 8. Capillary uptake of the HLP1 composite.

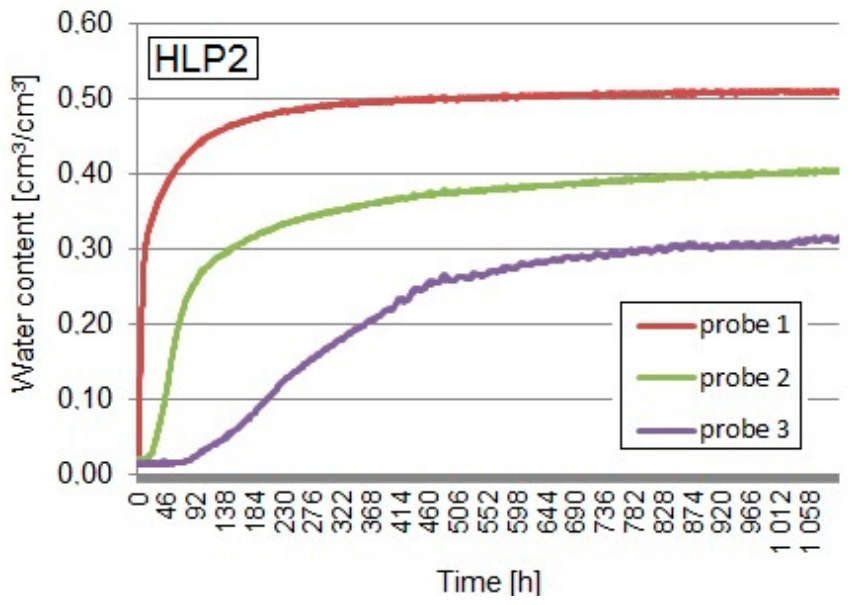

Figure 9. Capillary uptake of the HLP2 composite.

The maximum volumetric water content, measured by means of probe No.1 in the HL1 sample, containing the weight ratio of the binder to the filler $2: 1$ (apparent density of $497.9 \mathrm{~kg} / \mathrm{m}^{3}$ ), was equal to $54.2 \%$. In the coverage area of the probe No.2, located $75 \mathrm{~mm}$ above the water level, maximum moisture equaled $41.4 \%$, while, in the area of the probe No.3 influence, which was $125 \mathrm{~mm}$ above the water level, it amounted to $27.1 \%$. The dynamics of the capillary uptake process in this sample turned out to be the smallest. The moisture of the material in the area of probes No. 2 and 3 did not stabilize until the end of the study. The recipe in which the HL1 sample was made using the largest amount of binder contributed to limiting the dynamics of the capillary uptake process (also mass absorption, described earlier), as well as the decrease in the intensity of water uptake at different levels-the moisture in the higher part of the sample (probe No.3) at the end of the test was half the value of the moisture read at the bottom part of the sample (probe No.1). Comparing the results with the HLP1 sample (the same ratio of binder to filler), the presence of expanded perlite decreased material absorptivity but did not slow down the progress in the capillary rise phenomenon.

The maximum volumetric water content, measured by probe No.1 in the HLP1 sample, containing the weight ratio of the binder to the filler 2:1 (apparent density of $503.1 \mathrm{~kg} / \mathrm{m}^{3}$ ), was equal to $41.4 \%$. The content of hemp shives reached $60 \%$, and the expanded perlite $40 \%$ by weight of the total amount of filler. In the coverage area of the probe No.2, the moisture read was equal to $25.3 \mathrm{vol} \%$, while, in the coverage area of the probe No.3, it was about $21.8 \mathrm{vol} \%$. A dynamic increase in the water content at all measurement levels took place up to the sixth day of the test and was higher compared to the HL1 recipe, but, in the case of the volumetric water content, lower values were achieved.

The maximum volumetric water content, read by the probe No.1 in the sample HLP2, was $52.1 \%$. The weight ratio of the binder to the filler in this recipe was 1.5:1, and the apparent density of the 
composite was $417.5 \mathrm{~kg} / \mathrm{m}^{3}$. In the case of the probe No.2, the maximum moisture readouts reached $37.9 \mathrm{vol} \%$, while, in the coverage area of sensor No.3, it was $28.4 \mathrm{vol} \%$. The dynamic moisture growth could be seen in the area of the probes No.1 and 2 influence, in the bottom part of the sample, which was close to the water level. The volumetric water content readouts in the particular areas of the samples measured by the probes No. 2 and 3 were stabilized only around the 35th day of the study.

The readouts of the used TDR FP/mts probes showed the changes of moisture at particular levels over the water surface, which enabled to draw the moisture profiles at particular periods of time (only first 10 days + final readout). They are presented in Figures 10-12. The dashed lines indicate the profiles during the last day of the study.

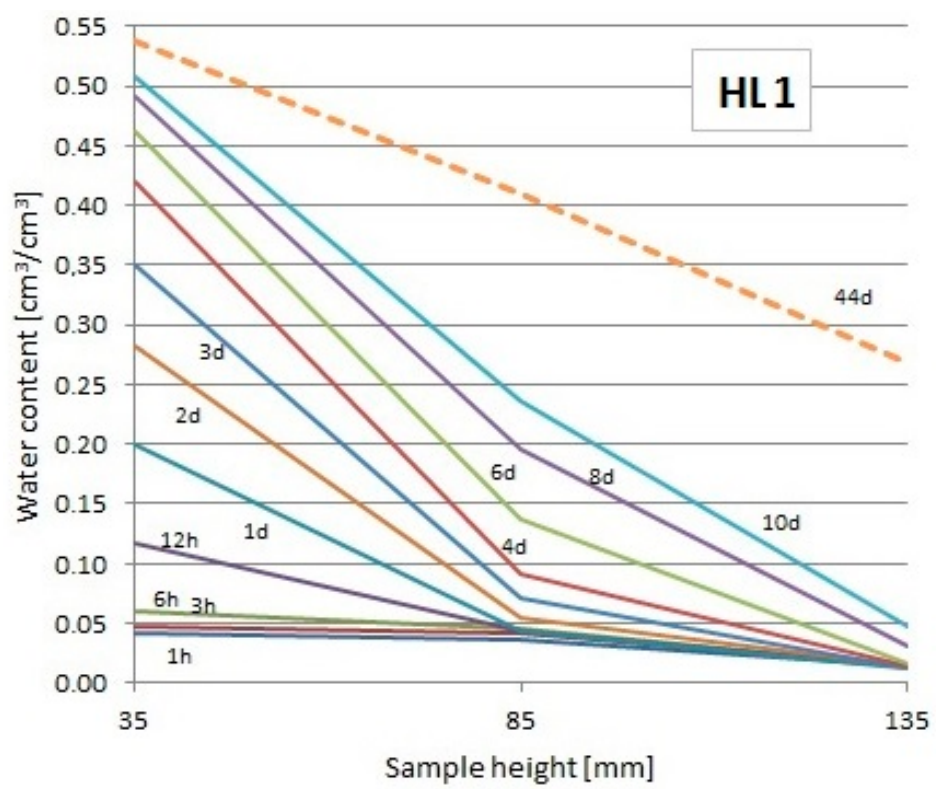

Figure 10. Moisture profiles obtained using the TDR measurement in particular intervals for the HL1 composite.

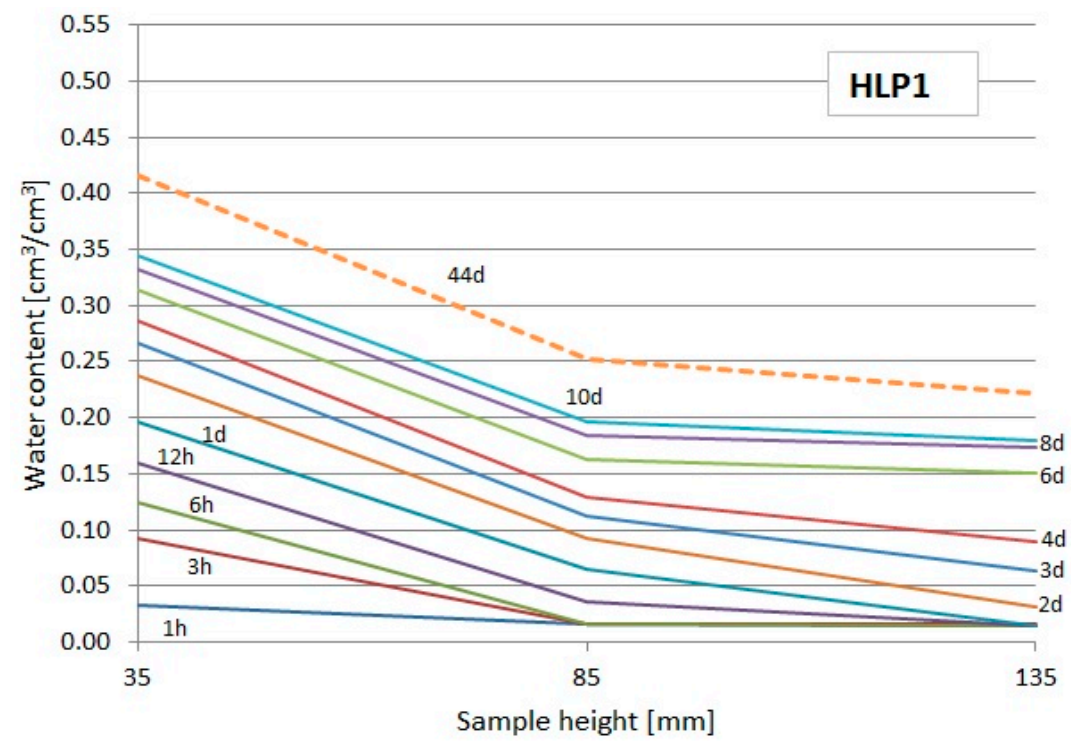

Figure 11. Moisture profiles obtained using the TDR measurement in particular intervals for the HLP1 composite. 


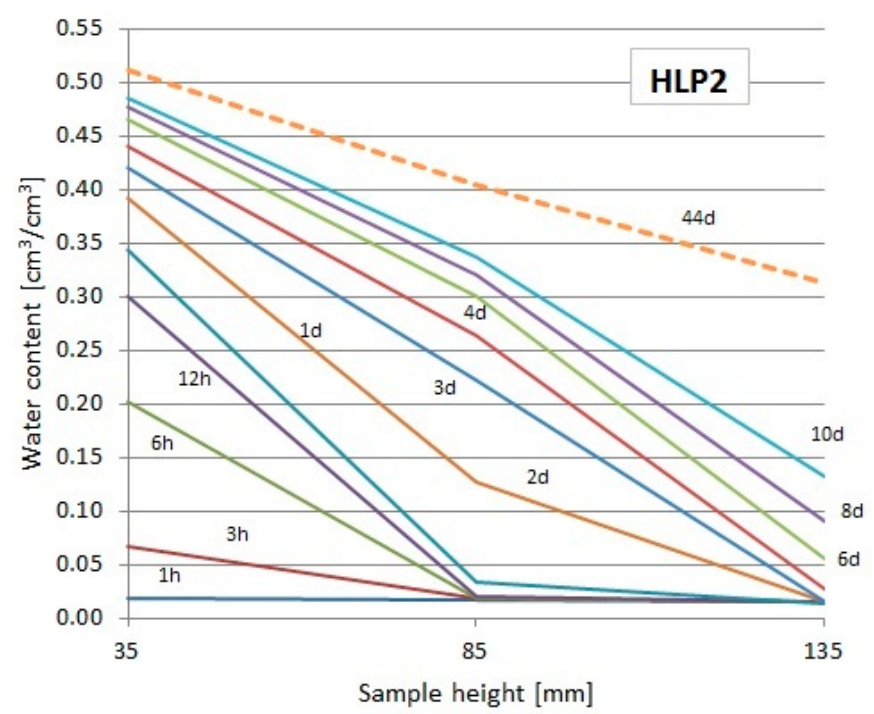

Figure 12. Moisture profiles obtained using the TDR measurement in particular intervals for the HLP2 composite.

From the diagrams presented in Figures 10-12, it could be noticed that the capillary uptake of moisture in particular composites differed in the particular types of composites. The presented profiles were used to evaluate the water absorption coefficient.

\subsection{Evaluation of Water Absorption Coefficient Using Standard and Reflectometric Technique}

With the moisture profiles obtained with TDR, the mass of absorbed water was calculated according to the following Equation (2). An analogous procedure was used in the studies on autoclaved aerated concrete $[59,60]$ :

$$
m=a \cdot b \int_{0}^{h} \theta(h) d h
$$

where $m$-mass of absorbed water (g); $a, b$-sample cross-section dimensions (width, depth); $h$-sample height; $\theta(h)$-moisture characteristics depending on height (moisture profile).

The graph (Figures 13 and 14) showed the mass of absorbed water in time intervals examined using the TDR method (Figure 13) and according to the EN 1925 standard (Figure 14).

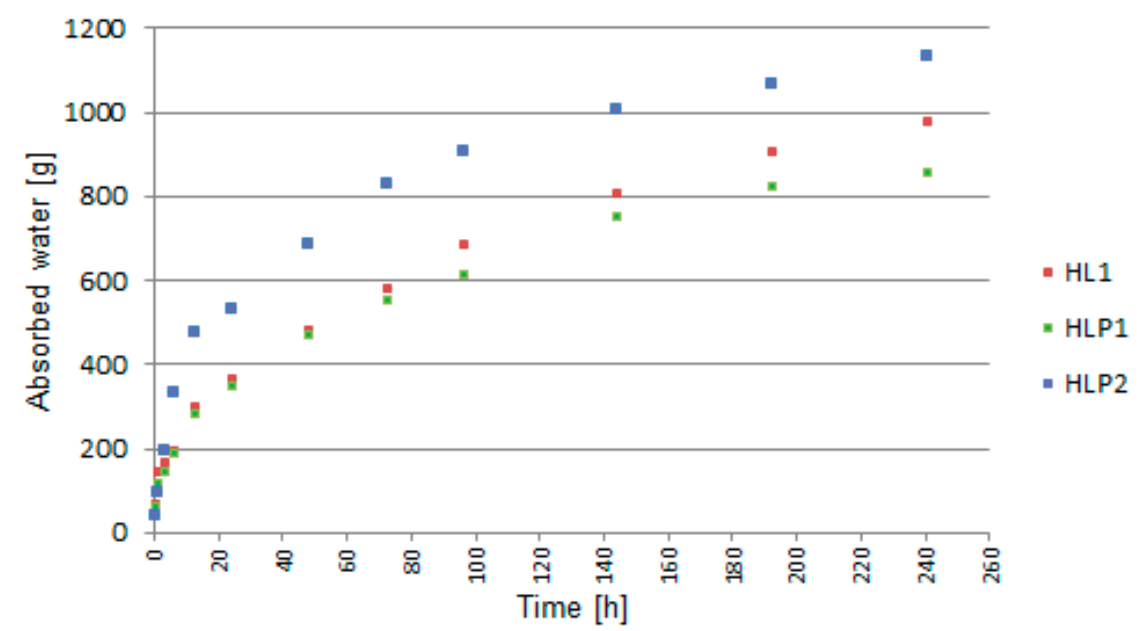

Figure 13. Water absorption by capillary uptake over time using the TDR method. 


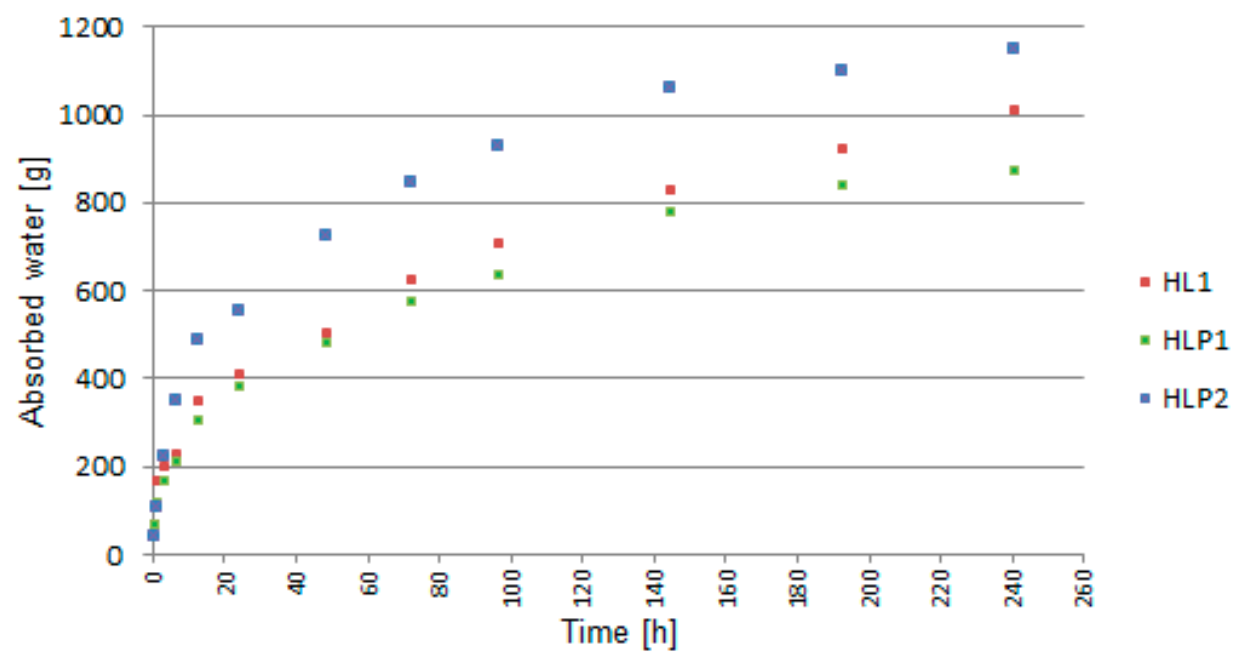

Figure 14. Water absorption by capillary uptake over time, according to the PN-EN 1925 standard method.

In both the methods, the tendency of the mass increase of samples was comparable in all tested recipes. The most dynamic water absorption occurred in the first second of contact of the dry sample with water. HLP1 and HL1 had the same binder to filler ratio but differed in the type of fillers, which caused differences in the amount of absorbed water. It could be noticed that the presence of perlite reduced the capillary rising ability of the composite. However, the ratio of binder to filler had a greater effect on the amount of water absorbed. The differences in the rate and magnitude of absorption were noticeable, especially between the group of HLP1 and HLP2 because of the different binder to filler ratio (2:1 and 1.5:1, respectively). A larger amount of binder sealed the pores of hemp shives more effectively. The highest amount of water was absorbed by the HLP2 composite, but showed lower moisture content by volume (Figures 6 and 8) compared to the HL1 composite, which absorbed about $150 \mathrm{~g}$ less water. This might be related to the smaller amount of binder contained in HLP2, which resulted in higher porosity. The water was accumulated on the pore walls (as evidenced by the readings from the probes, Figure 8), leaving the pores partially filled with water, thus taking a smaller part sample volume compared to HL1, containing a greater amount of binder.

On the basis of the literature [53], the capillary uptake coefficient was determined after $24 \mathrm{~h}$ of testing. The values obtained using the TDR method equaled $2.69,2.62$, and $4.45 \mathrm{~kg} / \mathrm{m}^{2} \mathrm{~h}^{1 / 2}$, and, by using the gravimetric method, they were equal to $2.76,2.68$, and $4.53 \mathrm{~kg} / \mathrm{m}^{2} \mathrm{~h}^{1 / 2}$ (for HL1, HLP1, and HLP2, respectively). As visible in the diagram, the HL1 and HLP1 composites were characterized by the similar values of the evaluated parameter. In the case of the HLP2 composite, the capillary uptake coefficient value was significantly higher and amounted to over $4 \mathrm{~kg} / \mathrm{m}^{2} \mathrm{~h}^{1 / 2}$. This was mainly caused by the lower share of the binder compared to the other recipes, and the air gaps between the shives were larger, and thus the absorptivity of the material was higher. Moreover, it should be noticed that the coefficient values determined using the TDR technology are underestimated for about $2 \%$ on average.

In the literature, there are reports on the capillary uptake of water examination on hemp-lime composites. They are mainly based on the EN 1925 standard, rather than the reflectometric techniques. Such an experiment has been described in [53], where the ability of capillary uptake of water by the lime-hemp composite with different recipes that differ in the binder and the weight ratio between binder and aggregate 2:1 has been described. The capillary uptake coefficient has been in the range between 2.65 and $3.37 \mathrm{~kg} / \mathrm{m}^{2} \mathrm{~h}^{1 / 2}$ within the first $24 \mathrm{~h}$ since dipping. The authors stated that the kind of a binder did not significantly influence the readouts; therefore, only one kind of a binder was used in the next examinations. In [61], it has been stated that the addition of methylocellulose to a binder 
influences the limitation of the capillary uptake phenomenon because it may create small pores in a binder that cut the path for the water to be raised.

The research of the capillary rise on the lime-hemp composite has also been presented in the research [62]. The composites that differed in the binder configuration (hydrated lime, hydraulic lime, Portland concrete) and weight ratio between shives and the binder (between 0.22 and 0.33 ) have been used for the investigation. In their research, the authors revealed no significant differences in the behavior of the material produced using all of the applied recipes. The average coefficient of capillary uptake is reported as $9 \mathrm{~kg} / \mathrm{m}^{2} \mathrm{~h}^{1 / 2}\left(0.15 \mathrm{~kg} / \mathrm{m}^{2} \mathrm{~s}^{1 / 2}\right)$.

In order to determine the similarity of the results of gravimetric and reflectometric tests, the graphs presented in Figure 15 were prepared to show the correlation.
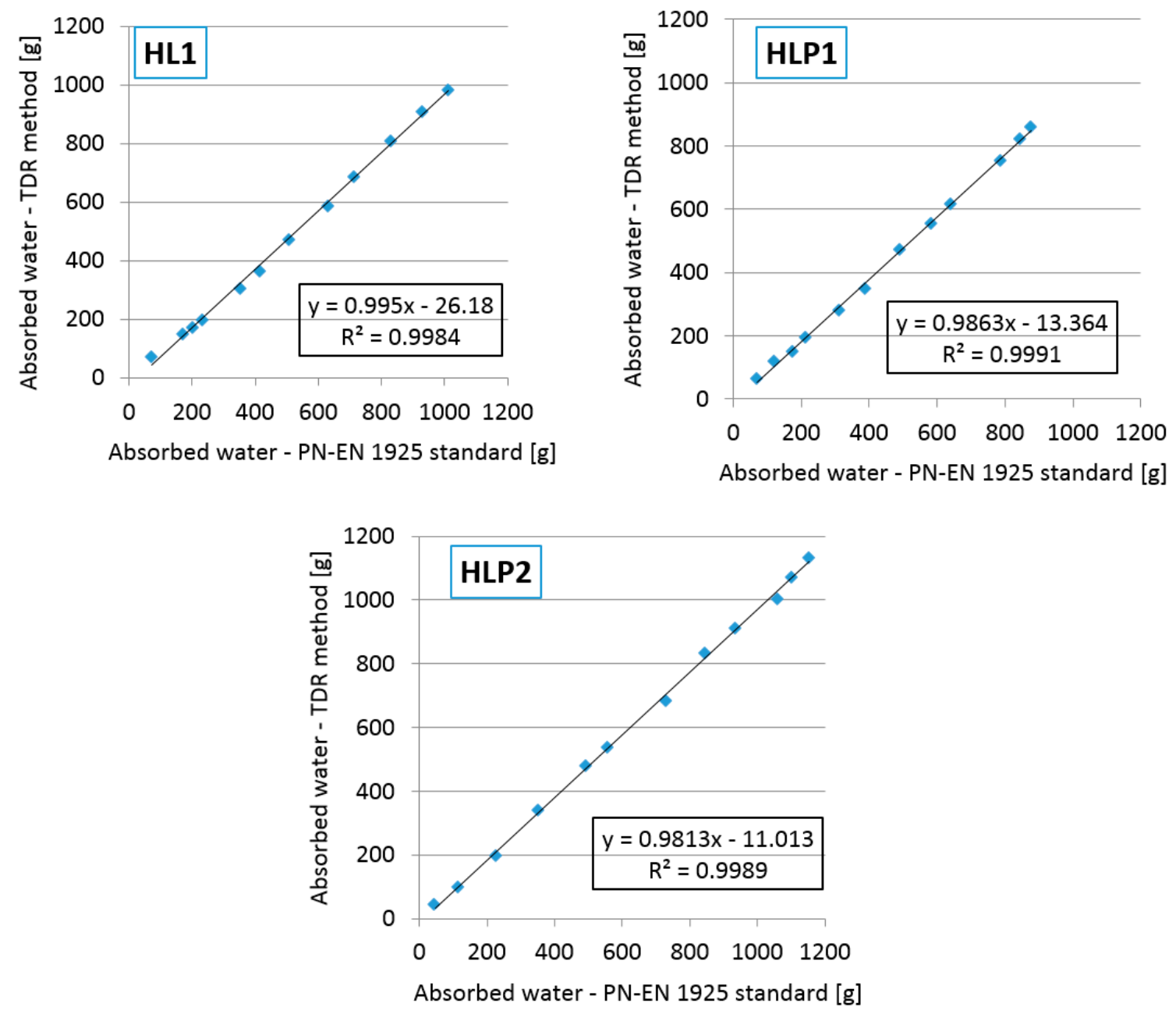

Figure 15. Correlations between the amount of absorbed water evaluated using the gravimetric method and the reflectometric one.

The differences in the results of the test performed with the two methods were not significant. The results obtained with the gravimetric method were $2.3-14.2 \%$ higher for the HL1 composite, $2.1-13.4 \%$ for HLP1, and 1.3-12.6\% for HLP2, in comparison with the results obtained by means of the TDR method in the adopted time intervals. Nevertheless, the correlation between the processes measured using both techniques was high. The dependences between the moisture readouts using both techniques of detection were linear, which was proven by the formulas evaluated in Figure 15 and coefficients of determination $\mathrm{R}^{2}$ reaching over 0.99 in each case. Moreover, the values of slopes of linear formulas equaled between 0.981 and 0.995 and were close to 1 . On the other hand, the y-intercept 
values of the linear correlation models were negative and between -11.01 and -26.18 , which meant that the reflectometric readouts were lower in the moisture value compared to the gravimetric evaluation.

\section{Conclusions}

The research presented the possibilities of using hemp shives and expanded perlite as an aggregate of an eco-friendly composite based on a lime binder for use as wall filling. The basic properties of composites and their ability of capillary uptake of water were investigated.

A thorough analysis of the capillary uptake results enabled to formulate the following conclusions:

- The maximum volumetric water content in the tested composites was from 41.4 to $54.2 \mathrm{~cm}^{3} / \mathrm{cm}^{3}$ (based on the TDR method). The highest volumetric water content of the sample was demonstrated by the HL1 composite, while the smallest by the HLP1 composite.

- The maximum volumetric water content measured using the TDR equipment nearly reached the value of volume absorptivity of all samples determined in pre-tests. On average, the reflectometric readouts were underestimated for 2.5-3.5\% (HLP2 and HL1 samples) and for 9.4\% (HLP1 sample).

- Mass of the absorbed water determined with the gravimetric method was higher by $1.3-3.0 \%$ in comparison with the results obtained using the TDR method. The HL1 sample showed the largest differences, whereas HLP2 showed the smallest.

- In general, the Time Domain Reflectometry readouts of the moisture properties of the examined composites were underestimated for about $2 \%$ compared to the gravimetric evaluation. This could be the consequence of the applied universal calibration model but also measuring uncertainty.

- The ratio of binder to filler had a greater effect on limiting the water absorption due to the capillary uptake than the kind of filler.

- Comparing composites with the same ratio of binder to filler (HL1 and HLP1), less water absorption due to the capillary uptake was exhibited by the composite containing expanded perlite (about $14.5 \%$ lower).

- The HL1 and HLP1 composites were characterized by similar values of the water absorption coefficient values $\left(2.62-2.76 \mathrm{~kg} / \mathrm{m}^{2} \mathrm{~h}^{1 / 2}\right.$ based on both methods of testing). In the case of the HLP2 composite, the coefficient value was significantly higher and amounted to over $4 \mathrm{~kg} / \mathrm{m}^{2} \mathrm{~h}^{1 / 2}$.

- The mass absorptivity of composites was $90.1-127.8 \%$. The most dynamic water absorption occurred in the first seconds after the immersion of samples in water. The absorptivity of the HL1 sample after $5 \mathrm{~s}$ was $42.7 \%$. The presence of expanded perlite resulted in a reduction of the initial water absorption.

On the basis of the test results of other measured properties, the following conclusions were drawn:

- Composites had an apparent density of $417.5-503.1 \mathrm{~kg} / \mathrm{m}^{3}$. Partial replacement of hemp shives with perlite reduced the density by about $1 \%$. Lowering the proportion of binder to filler from 2:1 to $1.5: 1$ reduced the density by $20.5 \%$.

- Composites were characterized by low values of flexural (0.16-0.23 MPa) and compressive strength (0.55-0.78 MPa). The highest parameters were shown by the HLP1 composite, while the smallest by the HLP2 composite. Partial replacement of the shives with perlite resulted in an increase in the strength parameters.

- Hemp-lime composites were characterized by the thermal conductivity in the range of $0.087-0.111$ $\mathrm{W} /(\mathrm{m} \cdot \mathrm{K})$. Partial replacement of hemp shives with perlite affected the difference in the thermal conductivity coefficient of the HL1 sample to a limited extent; the sample had an average lambda value lower by $2.8 \%$ than HLP1.

Author Contributions: Conceptualization, P.B. and Z.S.; Data curation, P.B. and Z.S.; Formal analysis, P.B. and Z.S.; Funding acquisition, P.B. and Z.S.; Investigation, P.B. and Z.S.; Methodology, P.B. and Z.S.; Project 
administration, P.B. and Z.S.; Resources, P.B.; Software, Z.S.; Supervision, P.B. and Z.S.; Writing—original draft, P.B. and Z.S.; Writing-review and editing, P.B. and Z.S. All authors have read and agreed to the published version of the manuscript.

Funding: This research was financially supported by the Ministry of Science and Higher Education in Poland within the statutory research of scientific units under subvention for the science program.

Conflicts of Interest: The authors declare no conflict of interest.

\section{References}

1. Collet, F.; Pretot, S. Thermal conductivity of hemp concretes: Variation with formulation, density and water content. Constr. Build. Mater. 2014, 65, 612-619. [CrossRef]

2. Binici, H.; Eken, M.; Dolaz, M.; Aksogan, O.; Kara, M. An environmentally friendly thermal insulation material from sunflower stalk, textile waste and stubble fibres. Constr. Build. Mater. 2014, 51, 24-33. [CrossRef]

3. Izquierdo, I.S.; Ramalho, M.A. Elements of structural masonry reinforced with sisal fibers. J. Civ. Eng. Archit. 2013, 7. [CrossRef]

4. Sam-Brew, S.; Smith, G.D. Flax and Hemp fiber-reinforced particleboard. Ind. Crop. Prod. 2015, 77, 940-948. [CrossRef]

5. Mostefai, N.; Hamzaoui, R.; Guessasma, S.; Aw, A.; Nouri, H. Microstructure and mechanical performance of modified hemp fibre and shiv mortars: Discovering the optimal formulation. Mater. Des. 2015, 84, 359-371. [CrossRef]

6. Kymalainen, H.R.; Sjoberg, A.M. Flax and hemp fibres as raw materials for thermal insulations. Build. Environ. 2008, 43, 1261-1269. [CrossRef]

7. Grudzińska, M.; Brzyski, P. The Occurrence of Thermal Bridges in Hemp-Lime Construction Junctions. Period. Polytech. Civ. Eng. 2019, 63, 377-387. [CrossRef]

8. Sinka, M.; Bajare, D.; Gendelis, S.; Jakovics, A. In-situ measurements of hemp-lime insulation materials for energy efficiency improvement. Energy Procedia 2018, 147, 242-248. [CrossRef]

9. Lawrence, M.; Heath, A.; Walker, P. Determining moisture levels in straw bale construction. Constr. Build. Mater. 2009, 23, 2763-2768. [CrossRef]

10. Minke, G.; Mahlke, F. Building with Straw; Birkhauser: Basel, Switzerland, 2005.

11. Rirsch, E.; Zhang, Z. Rising damp in masonry walls and the importance of mortar properties. Constr. Build. Mater. 2010, 24, 1815-1820. [CrossRef]

12. Hoła, J.; Matkowski, Z.; Schabowicz, K. Tomografia zawilgoconych murów ceglanych. Czas. Tech. B 2007, 104, 73-81.

13. Jerman, M.; Keppert, M.; Výborný, J.; Černý, R. Hygric, thermal and durability properties of autoclaved aerated concrete. Constr. Build. Mater. 2013,41, 352-359. [CrossRef]

14. PN-EN 1925:1999. Natural stone test methods. In Determination of Water Absorption Coefficient by Capillarity; Polish Committee for Standardization: Warsaw, Poland, 1999.

15. Topp, G.C.; Davis, J.L.; Annan, A.P. Electromagnetic determination of soil water content: Measurements in coaxial transmission lines. Water Resour. Res. 1980, 16, 574-582. [CrossRef]

16. Noborio, K. Mesurement of soil water content and electrical conductivity by time domain reflectometry: A review. Comput. Electron. Agric. 2001, 31, 213-237. [CrossRef]

17. Wiener, O. Die Theorie des Mischkoerpers fuer das Feld der sta-tionaeren Stroemung. Abandlungen Math. 1912, 32, 509-604.

18. Polder, D.; Van Santen, J.H. The effective permeability of mixtures of sol-ids. Physica 1946, 12, $257-271$. [CrossRef]

19. De Loor, G.P. Dielectric properties of heterogeneous mixtures contain-ing water. J. Microw. Power 1968, 3 , 67-73. [CrossRef]

20. Tinga, W.R.; Voss, W.A.G.; Blossey, D.F. Generalized approach to multiphase dielectric mixture theorie. J. Appl. Phys. 1973, 44, 3897-3902. [CrossRef]

21. Birchak, J.R.; Gardner, C.G.; Hipp, J.E.; Victor, J.M. High dielectric constant microwave probes for sensing soil moisture. Proc. IEEE 1974, 62, 93-98. [CrossRef] 
22. Roth, K.; Schulin, R.; Flühler, H.; Attinger, W. Calibration of time do-main reflectometry for water content measurement using a composite die-lectric approach. Water Resour. Res. 1990, 26, 2267-2273.

23. Malicki, M.A.; Plagge, R.; Roth, C.H. Improving the calibration of dielectric TDR soil moisture determination taking into account the solid soil. Eur. J. Soil Sci. 1996, 47, 357-366. [CrossRef]

24. Davis, J.L.; Annan, A.P. Ground-penetrating radar for high-resolution mapping of soil and rock stratigraphy. Geophys. Prospect. 1989, 37, 351-551. [CrossRef]

25. Malicki, M.A.; Skierucha, W.M. A manually controlled TDR soil moisture meter operating with 300ps rise-time needle pulse. Irrig. Sci. 1989, 10, 153-163. [CrossRef]

26. Korhonen, C.J.; Janoo, V.C.; Berini, C.M. Time-Domain Reflectometry of Water Content in Portland Cement Concrete; Cold Regions Research \& Engineering Laboratory: Hanover, NH, USA, 1997.

27. Skierucha, W.; Wilczek, A.; Alokhina, O. Calibration of a TDR probe for low soil water content measurements. Sensors and Actuators A 2008, 147, 544-552. [CrossRef]

28. De Hansen, E.J.P.; Hansen, M.H. TDR measurement of moisture content in aerated concrete. In 6 th Symposium on Building Physics in the Nordic Countries; Norwegian University of Science and Technology: Trondheim, Norway, 2002; pp. 381-388.

29. Pavlík, Z.; Cerný, R. Application of TDR measurement technology for construction materials in semi-scale experiments. Int. Agrophysics 2004, 18, 249-252.

30. Pavlík, Z.; Fiala, L.; Černý, R. Determination of Moisture Content of Hygroscopic Building Materials Using Time Domain Reflectometry. J. Appl. Sci. 2008, 8, 1732-1737. [CrossRef]

31. Chabriac, P.A.; Fabbri, A.; Morel, J.C.; Laurent, J.P.; Blanc-Gonnet, J. A Procedure to Measure the in-Situ Hygrothermal Behavior of Earth Walls. Materials 2014, 7, 3002-3020. [CrossRef]

32. Barnat-Hunek, D.; Smarzewski, P.; Suchorab, Z. Effect of hydrophobisation on durability related properties of ceramic brick. Constr. Build. Mater. 2016, 111, 275-285. [CrossRef]

33. Suchorab, Z.; Jedut, A.; Sobczuk, H. Water content measurement in building barriers and materials using surface TDR probe. Proc. Ecopole 2008, 2, 123-127.

34. Suchorab, Z.; Widomski, M.K.; Łagód, G.; Barnat-Hunek, D.; Majerek, D. A Noninvasive TDR Sensor to Measure the Moisture Content of Rigid Porous Materials. Sensors 2018, 18, 3935. [CrossRef]

35. Brzyski, P.; Łagód, G. Physical and mechanical properties of composites based on hemp shives and lime. E3s Web Conf. 2018, 49. [CrossRef]

36. Rahim, M.; Douzane, O.; Tran Le, A.D.; Promis, G.; Laidoudi, B.; Crigny, A.; Dupre, B.; Langlet, T. Characterization of flax lime and hemp lime concretes: Hygric properties and moisture buffer capacity. Energy Build. 2015, 88, 91-99. [CrossRef]

37. Perlit-Polska Website Dedicated to Building \& Constructions. Available online: http://perlit-polska.pl (accessed on 14 March 2020).

38. Hirst, E.; Walker, P.; Paine, K.; Yates, T. Characterisation of low density hemp-lime composite building materials under compression loading. In Proceedings of the 2nd International Conference on Sustainable Construction Materials and Technologies, Ancona, Italy, 28-30 June 2010.

39. Gourlay, E.; Arnaud, L. Comportementhygrothermique des murs de béton de chanvre. In Proceedings of the Actes du Congrès SFT, Le Touquet, France, 25-28 May 2010.

40. Cerezo, V. Propriétésmécaniques, Thermiquesetacoustiques d'un Matériau à Base de Particulesvégétales: Approcheéxpérimentale et Modélisationthéorique; L’Institut National des Sciences Appliquées de Lyon: Saint Valérien, France, 2005.

41. Nguyen, T. Contribution à L'étude de la Formulation et du Procédé de Fabrication D'éléments de Construction Enbéton de Chanvre. Ph.D. Thesis, Université de Bretagne Sud, Morbihan, France, 2010.

42. PN-EN 12390-3:2019-07. Testing hardened concrete-Part 7: Density of Hardened Concrete; Polish Committee for Standardization: Warsaw, Poland, 2019.

43. PN-EN 13755:2008. Natural Stone Test Methods Determination of Water Absorption at Atmospheric Pressure; Polish Committee for Standardization: Warsaw, Poland, 2008.

44. Amato, M.; Ritchie, J.T. Small spatial scale soil water content measurement with time-domain reflectometry. Soil Sci. Soc. Am. J. 1995, 59, 325-329. [CrossRef]

45. Vett, S.R. Soil Water Measurement by Time Domain Reflectometry; Dekker, M., Ed.; Encyclopedia of Water Science, Inc.: New York, NY, USA, 2003; pp. 894-898. 
46. Černý, R. Time-domain reflectometry method and its application for measuring moisture content in porous materials: A review. Measurement 2009, 42, 329-336. [CrossRef]

47. Arnaud, L.; Gourlay, E. Experimental study of parameters influencing mechanical properties of hemp concretes. Constr. Build. Mater. 2012, 28, 50-56. [CrossRef]

48. Benfratello, S.; Capitano, C.; Peri, G.; Rizzo, G.; Scaccianoce, G.; Sorrentino, G. Thermal and structural properties of a hemp-lime biocomposite. Constr. Build. Mater. 2013, 48, 745-754. [CrossRef]

49. Elfordy, S.; Lucas, F. Mechanical and thermal properties of lime and hemp concrete ("hempcrete") manufactured by a projection process. Constr. Build. Mater. 2008, 22, 2116-2123. [CrossRef]

50. Rahim, M.; Douzane, O.; Tran Le, A.D.; Promis, G.; Langlet, T. Characterization and comparison of hygric properties of rape straw concrete and hemp concrete. Constr. Build. Mater. 2016, 102, 679-687. [CrossRef]

51. Barclay, M.; Holcroft, N.; Shea, A.D. Methods to determine whole building hygrothermal performance of hemp-lime buildings. Build. Environ. 2014, 80, 204-212. [CrossRef]

52. Gross, C.; Walker, P. Racking performance of timber studwork and hemp-lime walling. Constr. Build. Mater. 2014, 66, 429-435. [CrossRef]

53. Walker, R.; Pavía, S. Moisture transfer and thermal properties of hemp-lime concretes. Constr. Build. Mater. 2014, 64, 270-276. [CrossRef]

54. Tran Le, A.; Maalouf, C.; Mai, T.H.; Wurtz, E.; Collet, F. Transient hygrothermal behaviour of a hemp concrete building envelope. Energy Build. 2010, 42, 1797-1806. [CrossRef]

55. Chabannes, M.; Garcia-Diaz, E.; Clerc, L.; Bénézet, J.C. Effect of curing conditions and $\mathrm{Ca}(\mathrm{OH})_{2}$-treated aggregates on mechanical properties of rice husk and hemp concretes using a lime-based binder. Constr. Build. Mater. 2016, 102, 821-833. [CrossRef]

56. Brzyski, P.; Widomski, M. The Influence of Partial Replacement of Hemp Shives by Expanded Perlite on Physical Properties of Hemp-Lime Composite. Aip Conf. Proc. 2017, 1866. [CrossRef]

57. Stevulova, N.; Kidalova, L.; Cigasova, J.; Junak, J.; Sicakova, A.; Terpakova, E. Lightweight Composites Containing Hemp Hurds. Procedia Eng. 2013, 65, 69-74. [CrossRef]

58. Sassoni, E.; Manzi, S.; Motori, A.; Montecchi, M.; Canti, M. Novel sustainable hemp-based composites for application in the building industry: Physical, thermal and mechanical characterization. Energy Build. 2014, 77, 219-226. [CrossRef]

59. Suchorab, Z.; Majerek, D.; Brzyski, P.; Sobczuk, H.; Raczkowski, A. Estimation of water absorption coefficient using the TDR method. Aip Conf. Proc. 2017, 1866, 040038. [CrossRef]

60. Suchorab, Z.; Brzyski, P.; Raczkowski, A.; Garbacz, M.; Życzyńska, A. Laboratory Determination of Hygric and Thermal Anisotropy of Aerated Concrete. Aip Conf. Proc. 2018, 1988, 020045. [CrossRef]

61. Paiva, H.; Esteves, L.P.; Cachim, P.B.; Ferreira, V.M. Rheology and hardened properties of single-coat render mortars with different types of water retaining agents. Constr. Build. Mater. 2009, 23, 1141-1146. [CrossRef]

62. Brigitte de Bruijn, P.; Jeppsson, K.H.; Sandin, K.; Nilsson, C. Mechanical properties of lime-hemp concrete containing shives and fibres. Biosyst. Eng. 2009, 103. [CrossRef]

(C) 2020 by the authors. Licensee MDPI, Basel, Switzerland. This article is an open access article distributed under the terms and conditions of the Creative Commons Attribution (CC BY) license (http://creativecommons.org/licenses/by/4.0/). 